\title{
INTERVENÇÃO HUMANITÁRIA X SOBERANIA: A RELATIVIZAÇÃO DO PRINCÍPIO DA NÃO INTERVENÇÃO PARA FINS DE PROTEÇÃO DOS DIREITOS HUMANOS
}

\author{
HUMANITARIAN INTERVENTION X \\ SOVEREIGNTY: THE RELAXATION OF THE \\ PRINCIPLE OF NON-INTERVENTION FOR THE \\ PURPOSE OF PROTECTING HUMAN RIGHTS
}

\section{Carla Patricia Finatto ${ }^{1}$}

Resumo: Ante as diversas crises humanitárias atuais e aquelas já enfrentadas, faz-se necessário destacar o debate acerca da conciliação do conceito de soberania e da flexibilização do princípio da não intervenção, eis que um dos mais relevantes choques axiológicos do cenário internacional ocorre entre os conceitos de soberania e direitos humanos. O presente artigo busca, portanto, abordar o conflito entre os conceitos de intervenção humanitária e soberania a fim de demonstrar a possível - e necessária - flexibilização do princípio da não intervenção. Por fim, apreciar-se-á o conceito, bem como a legalidade e a legitimidade do instituto da intervenção humanitária com objetivo de sustentar a ideia de que a comunidade internacio- nal tem o direito, e até mesmo o dever, de realizá-las.

Palavras-chave: Intervenção humanitária. Soberania. Direitos humanos. Princípio da não intervenção.

Abstract: Given the current humanitarian crises and those already faced, it is necessary to highlight the debate about the conciliation of the concept of sovereignty and the flexibilization of the principle of nonintervention, since one of the most relevant axiological shocks of the international scenario occurs between the concepts of sovereignty and human rights. Therefore, the present article seeks to address the conflict between the concepts of humanitarian intervention and

1 Formada em Direito pela Faculdade Cesusc, Pós-Graduadanda em Direito Internacional Aplicado pela EBRADI, especialista em Direitos Humanos pela Universidade Pablo de Olavide - Sevilha/Espanha, Ex-aluna da Esmesc, Módulo I e Residência Judicial. E-mail: carla_finatto@hotmail.com 
sovereignty in order to demonstrate the possible - and necessary - flexibilization of the principle of nonintervention. Finally, the concept, as well as the legality and legitimacy of the institute of humanitarian intervention, will be appreciated in order to support the idea that the international community has the right, and even the duty, to carry them out.

Keywords: Humanitarian Intervention. Sovereignty. Human Rights. Principle of Nonintervention.

\section{INTRODUÇÃO}

O presente trabalho elegeu por tema o estudo dos institutos da soberania dos estados, da não intervenção e de sua flexibilização em determinados casos, eis que não existe uma norma que autorize expressamente a intervenção humanitária. Muito pelo contrário: a Carta da Organização das Nações Unidas estabelece o princípio da não intervenção como norteador da conduta dos Estados no âmbito internacional. Há duas exceções a esse princípio: (i) legítima defesa individual ou coletiva; (ii) quando o Conselho de Segurança (CS) determinar que uma situação constitui uma ameaça à paz ou segurança internacional.

O objetivo, portanto, é questionar se o disposto no art. 2.4 da Carta da ONU trata de uma proibição geral do uso da força, ou se este artigo pode e deve ser expandida para acomodar outros princípios fundamentais da ONU, como os direitos humanos, sendo que, para tanto, os Estados terão que, caso a caso, interpretar o art. 2.4 da Carta das Nações Unidas para poder autorizar uma intervenção humanitária.

Para isso, buscar-se-á demonstrar que a intervenção humanitária é possível, como último recurso em casos extremos, quando: (i) há - ou existe a ameaça - graves violações de direitos humanos em grande escala; (ii) a intervenção militar é o único meio para acabar ou prevenir a perda de vidas. Ou seja, há a necessidade de preenchimento de alguns requisitos para que possa haver intervenção humanitária.

Dessa forma, colocar-se-á em choque noções de soberania. 
Isso porque, para tratar-se de intervenção humanitária, é necessário que se compreenda que não há Estado absolutamente independente, nem se pode invocar a soberania estatal como escudo de proteção para evitar que se proteja e promova os direitos humanos de indivíduos que estão tendo esses direitos violados dentro das fronteiras dos Estados.

Neste último ponto considerar-se-á, ainda, o princípio da autodeterminação, a legalidade e a legitimidade das intervenções humanitárias, a fim de esclarecer a flexibilização do princípio da não intervenção bem como a relação da intervenção humanitária.

\section{INTERVENÇÃO HUMANITÁRIA X SOBERANIA}

O entendimento acerca da relação entre Estado e soberania é relevante porque a prática da intervenção humanitária demonstra uma alteração, ainda que bastante limitada, desta escala de valores que eleva a soberania como fundamento principal da manutenção da ordem entre os Estados (RODRIGUES, 2000, p. 167).

Porém, a interpretação dada ao termo soberania pelos estudiosos da área não aponta para um conceito comum. Diante desse debate que consiste a busca do conceito de soberania, o Suplemento do Relatório do International Commission on Intervention and State Sovereignty (ICISS), citando Schrijver, expõe as divergências da questão nos seguintes termos:

Poucos assuntos no direito internacional e nas relações internacionais são tão sensíveis como a noção de soberania. Steinberger se refere à ela na Enciclopédia de Direito Internacional Público como "a noção mais brilhante e controversa da história, da doutrina e da prática do direito internacional. Por outro lado, Henkin procura bani-la do vocabulário e Lauterpacth a chama de uma "palavra que 
tem uma emotiva qualidade sem conteúdo específico significativa", enquanto Verzijl observa que qualquer discussão sobre este assunto arrisca degenerar em uma Torre de Babel. Mais afirmativamente, Brownlie vê soberania como "a doutrina constitucional básica do direito das nações" e Alan James a vê como "o único princípio organizador em relação à seca superfície do globo, toda aquela superfície agora [...] dividida em entidades de soberania próprias ou constitucionalmente independentes. Como observado por Falk, "Há pouco campo neutro quando se trata de soberania” (ICISS, 2001, p. 5, tradução nossa).

É por não haver consenso sobre seu conceito, buscar-se-á apresentar características de sua construção, bem como a forma que essa tem sido entendida e utilizada como princípio norteador das relações internacionais.

A primeira é sua relação com o Estado. Nesse ponto, cumpre lembrar que, em princípio, todo Estado é independente no que se refere à administração de seus próprios assuntos e qualquer interferência externa constitui uma violação de sua soberania.

Alexandre de Moraes (2012, p. 03) entende que "O Estado, na tradicional obra de Jelinek, necessita de três elementos fundamentais: poder/soberania, população e território." Assim, o território, a população e a soberania são os três elementos que compõem o Estado. A população do país fica submetida ao Estado, que detém o poder de legislar sobre assuntos que regem todo o seu território. Nessa relação, a população torna-se subordinada ao Estado, revelando então um elemento essencial ao mesmo, que é o governo soberano.

O sistema internacional, contudo, nem sempre foi organizado em torno da ideia de soberania. Isso porque, antes do Tratado de Vestfália de 1648, a regra era a existência de jurisdições de autoridades políticas, com ausência de hierarquia entre elas. Exemplo desse modelo é o sistema feudal, no qual se tinham vínculos difusos, descentralizados, e baseados em 
ligações pessoais, não territoriais, de forma simultânea e conflitante com o Papa, com os reis, duques etc. (REGIS, 2006, p. 02 apud CUSIMANO, 2006, p. 06).

Regis destaca ainda que na maioria das vezes, o elemento religioso era utilizado para justificar o sistema, vez que nesta época, as pessoas estavam sob o império das leis espirituais que, muitas vezes, se misturavam com as leis espaciais ou territoriais. Porém, com o advento das disputas pelo poder entre o papado e o Sacro Império Romano Germânico, essas instituições feudais foram se enfraquecendo, dando espaço para o surgimento de novas formas de organizações políticas, dentre elas o Estado moderno (REGIS, 2006, p. 06).

No mesmo sentido, afirma Hinsley (1972, p. 22, tradução nossa):

Neste sentido, o surgimento de formas de Estado é condição essencial para a noção de soberania, da ideia de que existe uma autoridade política definitiva e absoluta na comunidade. Em uma sociedade pré-estatal essa ideia não importa.

É importante observar que a partir das mudanças econômicas, políticas e conceituais houve também a separação do Estado da Igreja. Com isso, apenas o Estado passou a gozar da legitimidade para cobrar tributos e para impor serviço militar (KRASNER, 1999, p. 09 apud REGIS 2006, p. 04 ).

Regis ressalta, ainda, que o Estado soberano conseguiu propiciar mais conquistas, tanto militares, quanto comerciais, quando comparado com as antigas formas de organização política (CUSIMANO, 2000, p. 9 apud REGIS 2006, p. 03). Depois disso, surgiu um acordo entre as diversas elites dos Estados soberanos, no sentido de excluírem do sistema internacional qualquer outra forma de organização política, que não estivesse baseada na ideia de soberania, como, por exemplo, as cidades-Estado, ligas urbanas, ou Impérios. 
Dessa forma, internamente, permitiu-se que os governos se auto organizassem, podendo adotar a forma que quisessem, razão pela qual o Direito Internacional Costumeiro tem sido extremamente apolítico, no sentido de permitir que os Estados soberanos escolham qualquer forma de organização política interna (ROBERTSON, 2002, p. 174), desde que estes sejam reconhecidos pelos outros como soberano, dentro da sua jurisdição territorial.

Pode-se perceber com isso que Estado e Soberania são conceitos intrinsecamente vinculados, ao mesmo tempo que a noção de soberania consiste em atributo que qualifica o Estado e o destaca das demais entidades políticas, ao mesmo tempo em que serve como característica de igualdade entre os mesmos.

\section{O PRINCÍPIO DA AUTODETERMINAÇÃO DOS POVOS}

Estritamente ligado à soberania está o princípio da autodeterminação dos povos, o qual segundo Brownlie (2008, p. 480) consiste no

[...] o direito de grupos nacionais coesos ('povos') de escolherem para si próprios uma forma de organização política e a sua relação com outros grupos. Esta escolha pode consistir na independência como Estado, na associação com outros grupos formando um Estado federal, ou na autonomia ou assimilação formando um Estado unitário (não federal).

O princípio da autodeterminação, portanto, objetiva garantir a um povo a possibilidade de conduzir livremente sua vida política, econômica e cultural, segundo princípios democráticos.

O supracitado princípio, amplamente reconhecido, vez que foi consagrado na Carta das Nações Unidas, de 1945, e na Declaração sobre Princípios de Direito Internacional Relativos às Relações Amigáveis e Cooperação entre Estados, de 1970. 
$\mathrm{Na}$ Carta das Nações Unidas, o art. $1^{\circ}$, parágrafo $2^{\circ}$, dispõe como um dos propósitos da ONU o de desenvolver relações amistosas entre as nações, baseadas no respeito ao princípio da igualdade de direitos e da autodeterminação dos povos.

O princípio aparece novamente no art. 55 do mesmo documento sob a seguinte redação "Com o fim de criar condições de estabilidade e bem-estar, necessárias às relações pacíficas e amistosas entre as nações, baseadas no respeito ao princípio da igualdade de direitos e da autodeterminação dos povos". $\mathrm{O}$ art. 55, "c", da Carta ainda determina que a ONU deva promover "o respeito universal e efetivo dos direitos humanos e das liberdades fundamentais para todos, sem distinção de raça, sexo, língua ou religião".

A Declaração, por sua vez, traz possíveis hipóteses de aplicação do princípio da autodeterminação, afirmando que sejam "[...] o estabelecimento de um Estado soberano e independente, a livre associação ou integração com um Estado independente ou culminando em qualquer outro status politico determinado livremente por um povo".

O Pacto Internacional dos Direitos Econômicos, Sociais e Culturais e o Pacto Internacional dos Direitos Civis e Políticos, ambos de 1966, trazem em seu bojo, no art. $1^{\circ}$, que "todos os povos têm o direito à autodeterminação. Em virtude desse direito, determinam livremente seu estatuto político e asseguram livremente seu desenvolvimento econômico, social e cultural".

A partir da leitura dos citados artigos, pode-se compreender que este princípio serve como elemento fortalecedor do princípio da não-intervenção. No entanto, para o objetivo deste trabalho uma análise mais profunda se faz necessária.

Weldehaimanot (2012, p. 94) ensina que,

o texto da Declaração sobre Relações Amistosas e Cooperação entre Estados é especialmente importante, pois in- 
dicou que, em alguns casos, o direito à autodeterminação pode substituir a integridade territorial de um Estado e garantir a secessão.

Para o autor, a Resolução preceitua que para a integridade territorial de determinado Estado ser mantida, esse deve,

conduzir-se em conformidade com o princípio da igualdade de direitos e da autodeterminação dos povos [...] e, portanto, sob um governo que represente todo o povo que pertence ao território, sem distinção de raça, credo ou cor (WELDEHAIMANOT, 2012, p. 94).

Assim, para o autor, há uma autodeterminação interna, ou seja, que pode ser realizada sem afetar o território do Estado e outra externa, que afeta o território, também chamada de secessão ou autodeterminação externa (WELDEHAIMANOT, 2012, p. 95).

No tocante a autodeterminação interna que, como visto, consiste no reconhecimento de cada povo dentro do mesmo Estado, de participar das decisões do Estado e ter seus direitos sociais garantidos, inclusive direitos à cultura própria e política, destaca Raic (2002, p. 243) que esta pode se manifestar basicamente sobre três aspectos diferentes, sendo eles a) a autodeterminação de toda a população do Estado, b) de um povo etnicamente distinto, para o caso de Estados multinacionais, e c) também das minorias.

Assim, a autodeterminação interna da qual toda a população de um Estado está sujeita se refere ao fato dessa população ser considerada, para efeito da aplicação do princípio, um povo em sentido amplo, já que neste aspecto “[...] um 'povo' é definido territorialmente e considerações étnicas são essencialmente irrelevantes: uma comunidade já politicamente organizada como um Estado constitui um 'povo"” (RAIC, 2002, p. 244).

Cumpre destacar que a autodeterminação interna tem li- 
gação tênue com o direito à secessão, que pode ser definida como o surgimento de um novo Estado através da separação de um Estado predecessor sem que este deixe necessariamente de existir (PELLET, 2009. p. 584). Dessa forma, um povo só tem o direito à secessão quando, teoricamente, se lhe nega o exercício da autodeterminação. Em outras palavras, quando não é politicamente representado no Estado em que vive e/ou quando esse Estado não lhe garante seus direitos, com base em discriminações ilegais de qualquer natureza.

A secessão seria, dessa forma, como uma solução viável para por termo a guerras civis e solucionar crises étnicas geradas por divisões arbitrárias de territórios sem conhecimento ou respeito à realidade demográfica.

Assim, se esta autodeterminação interna não estiver sendo respeitada, ou seja, nos casos em que subgrupos não tenham garantidos seus direitos sociais, inclusive direitos à cultura própria e política passa-se a análise da figura da autodeterminação externa.

De acordo com Alair Pellet, a autodeterminação externa constitui uma,

Fórmula que exige uma definição complementar: se o caráter geograficamente separado e étnica ou culturalmente distinto de um território são indícios desta situação, somente a existência de um regime político, jurídico ou cultural discriminatório constitui um critério certo de não autonomia; a população do território é, por conseguinte, um 'povo colonial' vocacionado à independência (PELLET et al. 2009, p. 579, tradução nossa).

Outrossim, não seria legítima, ao Direito Internacional, a independência de um Estado que reconhece todos os povos que estão sob seu domínio, garantindo a esses, direitos iguais, a menos que empreendida em livre acordo com o Estado cujo território seria desmembrado. 
Entretanto, a compatibilização entre autodeterminação dos povos, que, no limite, poderia implicar a secessão de um povo de um Estado original e a criação de um novo Estado, consiste em um ponto de ampla discussão entre pensadores do direito internacional.

Destaca-se, para o objetivo do presente trabalho, o entendimento de Crawford (2006. p. 383-384), vez que assinala que a secessão pode ocorrer com suporte do princípio da autodeterminação dos povos ou em violação a esse, dependendo de ter sobrevindo, respectivamente, de uma unidade de autodeterminação que conta com o apoio da população interessada ou se foi feita simplesmente em relação ao Estado independente.

Ocorre que a secessão, na maioria das vezes, não ocorre de forma pacífica. Isso porque implica na perda de uma parcela de soberania de um determinado Estado e com ela um pouco da influência econômica e política.

\section{A RELATIVIZAÇÃO DO PRINCÍPIO DA NÃO- INTERVENÇÃO}

Foucault compreende que a soberania abarca o dever do Estado de proteger os indivíduos que se encontram em seu território, uma vez que esta entidade foi estabelecida pelo contrato social para prover proteção a seus nacionais, pois a sujeição dos indivíduos ao Estado parte de seu medo da morte, ou melhor, de sua "vontade de preferir a vida à morte" (FOUCAULT, 1999, p.110).

Em decorrência desse entendimento, a soberania não somente exige do Estado o dever de proteger os nacionais, como esse dever consiste no seu principal pressuposto. Isso, porque, se o Estado não for capaz de proteger seus nacionais, a ligação mútua entre o povo e o Estado se rompe, colocando em risco o próprio sentido de soberania. Assim, a existên- 
cia do Estado depende da sobrevivência de seus nacionais, do contrário, "[...] a soberania do Estado desaparece pura e simplesmente porque os indivíduos desse Estado desapareceram." (FOUCAULT, 1999, p.109).

Nesse viés, quando se incorpora à questão da soberania ao estudo sobre Intervenções Humanitárias, inevitavelmente, deve-se lembrar que, numa ordem anárquico-realista, os Estados mais fortes buscam poder, enquanto os mais fracos procuram se defender contra potenciais ameaças. Desse modo, as Intervenções Humanitárias podem ser vistas, pelos mais fracos, como uma verdadeira ameaça à sua segurança no cenário internacional.

Wheeler destaca a existência de duas escolas: a primeira que defende que os Estados fortes majoritariamente intervêm nos Estados fracos quando ela serve aos seus interesses geopolíticos e ou econômicos, e a segunda que afirma a possibilidade da intervenção em defesa dos direitos humanos, como no caso da intervenção militar humanitária (WHEELER, 2000. p. 27).

Assim, na ordem jurídica internacional, sobrepaira o princípio da não-intervenção que está diretamente ligado ao atributo da soberania do Estado. Amaral Júnior (2011, p. 218) ensina que de acordo com o princípio da não intervenção, nenhuma nação ou governante tem o direito de interferir no governo de outro Estado, vez que a intervenção é uma prática ilícita, pois contraria o consagrado princípio da não-intervenção (MELLO, 1997, p. 45).

No modelo jurídico idealizado pela Carta da ONU, o Estado é o ator principal das relações internacionais e a não-intervenção é, nesse sistema, corolário lógico do conceito de soberania, pois vincula explicitamente o direito de um Estado à independência ao dever de respeito da mesma pelos demais Estados. O princípio da não-intervenção, portanto, está direta- 
mente ligado ao princípio da soberania dos Estados e constitui uma necessidade no atual sistema internacional (AMARAL, 2003, p. 156).

O princípio da não intervenção encontra-se consolidado no art. $2^{\circ}$, parágrafo $7^{\circ}$ da Carta da ONU e prevê que nenhum dispositivo da presente Carta autorizará as Nações Unidas a intervirem em assuntos que dependam essencialmente da jurisdição de qualquer Estado ou obrigará os Membros a submeterem tais assuntos a uma solução.

Franck destaca que com esse princípio buscou-se evitar o uso unilateral da força pelos Estados. Assim sendo, na Carta da ONU existem várias limitações sérias ao uso da força pelos Estados-membros, os quais concordaram em evitar em suas relações internacionais a ameaça ou o uso da força contra a integridade territorial ou a independência política de qualquer Estado ou qualquer outra ação incompatível com os Propósitos das Nações Unidas (FRANCK, 2006, p. 02).

Essas limitações iniciais implicam, na prática, que a força somente pode ser legalmente utilizada em legítima defesa ou pela própria ONU, e mesmo nesses casos algumas restrições se aplicam.

Nesse sentido, destaca Maidana (2009, p. 108-109):

O mandato do Conselho de Segurança é o instrumento que dá origem a uma operação de paz, contendo sua estrutura e suas linhas gerais para a solução de um episódio em específico. É esse documento que dará, além disso, o fundamento jurídico da missão, enquadrando-a de acordo com a necessidade do contexto em que atuará numa ou noutra posição dentro do quadro jurídico das Nações Unidas (MAIDANA, 2009 p.108-109).

Dessa forma, o recurso à força na Carta da ONU é bem limitado, e textualmente não autoriza ações militares com propósitos humanitários. Liliana Lyra Jubilut ensina que: 
Essa falta de autorização expressa para intervenções humanitárias encontra-se no centro do dilema legal que tal prática coloca para o Direito Internacional, pois a necessidade de uso da força para propósitos humanitários tem aparecido com certa frequência sem que haja norma que a autorize (JUBILUT, 2011, p. 07).

Diante deste contexto, ressaltam-se as crises humanitárias da década de 1990 como a do Kuwait (1990), no Norte do Iraque (1991), na Somália (1992), na Iugoslávia (1992), em Ruanda e no Haiti (1994), e que inclui campanhas de limpeza étnica, assassinatos em massa, e um grande número de desabrigados e refugiados.

Simone Martins Rodrigues (2000, p. 113) relata que devido ao caos que essas crises humanitárias provocaram a proteção da população civil passou a constituir uma das prioridades das ações empreendidas pelas forças a serviço da ONU. Ainda, destaca, ainda, que as intervenções de caráter humanitário que ocorreram no pós Guerra Fria demonstram o flagrante e maciço desrespeito aos direitos humanos, á ineficiência dos meios convencionais de assistência humanitária consensual e á mobilização do Conselho de Segurança considerando questões que antes eram de responsabilidade exclusiva os Estados como matéria de preocupação internacional (RODRIGUES, 2000, p. 114).

Assim, a década de 1990 caracterizar-se-ia, segundo Andrei Koerner:

[...] por um duplo processo: de um lado, existe um avanço no reconhecimento e na proteção dos direitos humanos e, por outro lado, a situação política internacional mostra como estas relações estão ainda indefinidas, dada a proteção internacional seletiva dos direitos humanos, submetidas aos interesses geopolíticos das principais potências, assim como as reações de suas lideranças e de grupos políticos fundamentalistas, nacionalistas e defensores de outros particularismos, que contestam mudanças mais profundas no campo dos Direitos humanos (KOERNER, 2002, p. 89). 
No mesmo sentido, Breno Hermann salienta que:

Em função desse quadro, passou-se a invocar o desrespeito aos direitos humanos como fator de desestabilização, no sentido do capítulo VII da Carta da Organização das Nações Unidas (ONU) (“Ação em caso de ameaça à paz, ruptura da paz ou ato de agressão"), o que deu ensejo a considerações acerca da realização de intervenções armadas, seja no quadro conceitual das Nações Unidas seja mesmo fora deste [...] (HERMANN, 2011, p. 146).

Percebe-se que, embora inexista um consenso acerca da justiça de se considerar as intervenções humanitárias como um dever moral, grande parte dos autores as consideram perfeitamente permissíveis em situações em que haja grave violação de direitos humanos (HERMANN, 2011, p. 147).

No mesmo sentido, Alexandre Peña Ghisleni aduz que:

[...] o princípio da não intervenção sofre limitações na área de direitos humanos. Em primeiro lugar, deve ser analisado em conjunção com o inovador caráter internacional que a Carta atribui a essa área. A Carta faz a proteção e a promoção dos direitos humanos extrapolarem a consideração que lhes era comumente dada no âmbito nacional até então, ao torna-la um dos Propósitos e Princípios das Nações Unidas e ao garantir à ONU o direito de fazer recomendações e de tratar do tema em um de seus órgãos assessores. A aprovação da Declaração Universal dos Direitos Humanos afasta qualquer margem de dúvida de que a questão dos direitos humanos não seria de competência exclusivamente interna: se era verdade que a responsabilidade pela observância dos padrões de direitos humanos recaía primeiramente no âmbito nacional, a definição dos padrões a serem seguidos pelos Estados era feita primordialmente na esfera internacional (GHISLENI, 2011, p. 44).

Outrossim, tem-se que o princípio da não-intervenção deve ser flexibilizado quando em choque com violações de direitos humanos, a fim de que estes sejam preservados. Ademais, ao tornar os direitos humanos um dos Propósitos e 
Princípios das Nações Unidas e ao garantir à ONU o direito de fazer recomendações e de tratar o tema em um de seus órgãos assessores, bem como com a aprovação da Declaração Universal dos Direitos Humanos, foi afastada a percepção de que os direitos humanos eram matéria de exclusividade interna, colocando-os no cenário internacional.

A importância dos direitos humanos, portanto, já está reconhecida internacionalmente, as diversas crises humanitárias que ocorreram nos anos noventa fomentaram o debate acerca da criação de medidas para que eles fossem efetivamente respeitados (RODRIGUES, 2000, p. 110). Dessa forma, as intervenções humanitárias ocorridas no pós-Guerra Fria representam a transferência de uma certa parcela de atribuições tradicionalmente adstritas ao Estado - as referentes aos direitos humanos - que passaram a integrar a agenda internacional (RODRIGUES, 2000, p. 166).

Um exemplo de intervenção humanitária ocorreu no conflito bósnio quando, sob a liderança do líder comunista da resistência do nazismo, Josip Broz Tito, foi estabelecido o regime comunista na Iuguslávia, em 1945, que começou a ruir com sua morte, em 1980 (RODRIGUES, 2000, p.151). Na Bósnia, viviam pessoas de etnia sérvia, croata e muçulmana em proporções quase idênticas e, os conflitos e perseguições étnicas entre essas populações tomaram graves proporções. Em resposta, o Conselho de Segurança adotou a Resolução n. 743, de 21 de fevereiro de 1992, que criou a Força de Proteção das Nações Unidas (UNPROFOR), cuja finalidade era criar áreas protegidas pela ONU em locais estratégicos. Mesmo assim, os conflitos continuavam a se intensificar. Então, em 13 de agosto de 1992, o Conselho aprova a Resolução 7709, fundamentada no capítulo VII da Carta, que exigia que as partes colocassem um fim imediato às hostilidades, que concedessem ao Comitê Internacional da Cruz Vermelha acesso livre e seguro às víti- 
mas do conflito e convocava os Estados a utilizarem todos os meios necessários para facilitar a distribuição de ajuda humanitária aos civis necessitados (ONU, 1992).

Diante da má vontade dos países em colaborar com a implementação da referida Resolução e da oferta da força aérea por parte da OTAN (Organização do Atlântico Norte), o Conselho de Segurança, por meio da aprovação da Resolução n. 781, criou zonas de exclusão aéreas monitoradas pelos aviões daquela, cuja finalidade era escoltar os comboios de ajuda humanitária. Depois de verificada a ocorrência de inúmeras violações às determinações desta Resolução, o Conselho aprovou a Resolução n. 816, de 31 de março de 1993, em que autoriza expressamente a utilização da força para a defesa da região, sem, contudo, permitir o bombardeio de alvos no solo. Com isso, a ONU proporcionou, por via aérea, a distribuição de medicamentos e gêneros alimentícios aos povoados muçulmanos inacessíveis por meios terrestres e a UNPROFOR estabeleceu algumas áreas de segurança para a proteção de civis (RODRIGUES, 2000, p. 157).

Devido às ofensivas realizadas contra as referidas áreas, o Conselho de Segurança, outra vez sob o comando do Capítulo VII, adota a Resolução n. 819, em 16 de abril de 1993, a qual transformava a cidade de Srebrenica e seus arredores numa área de segurança sob a proteção da ONU, livre de ataques armados ou quaisquer atos hostis. Mas, novamente as forças rebeldes desrespeitaram a Resolução e efetuaram um verdadeiro massacre no local. Isto motiva a aprovação da Resolução n. 836, de 04 de junho de 1993, em que o Conselho de Segurança decide estender o mandato da UNPROFOR para deter os ataques contra as áreas de segurança, retirar as forças militares e paramilitares desses locais, monitorar o cessar-fogo, ocupar alguns pontos estratégicos e continuar a entrega de ajuda humanitária para a população. 
Todavia, apesar da participação do Conselho de Segurança ter sido bastante ativa, uma vez que adotou cerca de 50 resoluções a respeito do conflito, a atuação teve um resultado lamentável: além do elevado número de refugiados e mortos, afundou a antiga Iugoslávia num completo caos econômico e social (RODRIGUES, 2000, p. 161-162).

Ademais, apesar do Conselho de Segurança ter autorizado o uso da força, uma ação militar coletiva não foi empreendida nos moldes das intervenções anteriores. Ao contrário, a operação da Bósnia foi feita por uma força de manutenção da paz que ganhou autoridade do Capítulo VII da Carta e contou com o apoio dos aviões da OTAN (PINTO, 1996, p. 205).

Simone Martins Rodrigues destaca ainda que a ausência de interesses vitais na área explica porque países como EUA (Estados Unidos da América), Inglaterra e França recusaram a arriscar suas forças na Iugoslávia e que membros de menor peso no Conselho de Segurança estavam mais favoráveis a ações mais eficazes, mas não estavam em posição de patrociná-las (RODRIGUES, 2000, p. 163).

\section{CONCEITO, LEGALIDADE E LEGITIMIDADE DA INTERVENÇÃO HUMANITÁRIA}

Ao longo da história, muitos pensadores e juristas tentaram definir o conceito de intervenção e de intervenção humanitária, contudo, até hoje não há uma definição normativa fixada nos documentos de direito internacional. Entretanto, a expressão é comumente usada para descrever a interferência em um país, mediante uso da força, com objetivo de proteger vidas humanas. Dessa forma, cabe estabelecer algumas noções específicas que ajudaram a identificar o termo.

Primeiramente cumpre relembrar que

"[...] todo Estado é independente no que se refere à adminis- 
tração de seus próprios assuntos e qualquer interferência externa constitui uma violação de suas prerrogativas". (RODRIGUES, 2000, p.91). Neste sentido nota-se a presença do princípio da soberania que estabelece que o Estado goza de liberdade ou independência para realizar os atos que lhe convir, dentro dos limites fixados pelo Direito Internacional, sem necessitar do consentimento de qualquer outro Estado, bem como do princípio da não ingerência e que constitui "[...] o principal empecilho ao desenvolvimento de meios efetivos de proteção aos direitos humanos no nível internacional." (RODRIGUES, 2000, p. 91).

\section{Ensina Dinh, Daillier e Pellet que:}

A noção de domínio reservado aos Estados tem por consequência a interdição feita aos outros Estados de intervirem em matérias que deles dependem. Todavia, se o princípio da não intervenção - ou da não ingerência, as duas expressões são sinônimos - dos Estados em assuntos dos outros Estados é, indiscutivelmente, consagrada pelo direito positivo, os seus contornos precisos não são menos incertos (PELLET et al., 2003, p. 451-452).

Contudo, é preciso diferenciar, ainda que brevemente, intervenção de ajuda humanitária e para isso devemos considerar que a ajuda humanitária visa aliviar o sofrimento momentâneo de determinada população sem menção a ameaças ou ao uso da força e, normalmente, em comum acordo com o Estado que receberá o referido suporte e com as partes beligerantes.

Cabe salientar ainda que Intervenção Humanitária está totalmente ligada com a responsabilidade de proteger, uma vez que esta é uma forma daquela. Sobre isso é essencial analisar quem tem legitimidade para intervir, bem como de onde se origina essa legitimidade.

Visto que a ONU foi criada em um cenário internacional que optou por uma abordagem positivista e que valorizava a não intervenção como um reflexo da soberania estatal e, por isso, sua principal função era estabelecer um sistema de segu- 
rança coletivo para substituir o uso unilateral da força pelos Estados, a intervenção humanitária acaba tendo grandes obstáculos para sua implementação.

A questão se torna mais complexa, uma vez que, na Carta da ONU existem várias limitações severas ao uso da força pelos Estados-membros decorrentes da proibição da ameaça ou do recurso à força nas relações internacionais, consagrada no n. 4 do art. $2^{\circ}$ da Carta, e do princípio da não intervenção nos assuntos internos dos Estados, previsto no n. 7 do mesmo artigo. Por meio do disposto nesse artigo, os Estados concordaram em "evitar em suas relações internacionais a ameaça ou o uso da força contra a integridade territorial ou a independência política de qualquer Estado, ou qualquer outra ação incompatível com os Propósitos das Nações Unidas.”, quais sejam manter a paz e a segurança internacionais, desenvolver relações amistosas entre as nações, realizar a cooperação internacional para resolver os problemas mundiais de caráter econômico, social, cultural e humanitário, promovendo o respeito aos direitos humanos e às liberdades fundamentais, e ser um centro destinado a harmonizar a ação dos povos para a consecução desses objetivos comuns (JUBILUT, 2012, p. 06).

Essas limitações iniciais implicam, na prática, que a força somente pode ser legalmente utilizada em legítima defesa ou pela própria ONU e mesmo nesses casos algumas restrições se aplicam.

No tocante a legítima defesa, o art. 51 da Carta da ONU estabelece que essa pode ser individual ou coletiva, mas está limitada pelos requisitos de que (a) um ataque armado deve existir antes que tal direito possa ser exercitado, (b) o direito não mais será exercido a partir do momento em que a $\mathrm{ONU}$ passar a agir na situação, e (c) toda ação exercida em legítima defesa deve ser relatada ao Conselho de Segurança. 
Em relação ao uso da força pela própria ONU, o mesmo só está autorizado, segundo art. 42 da Carta da ONU, quando houver o objetivo de manter a paz e segurança internacionais. Assim, o uso da força na Carta é bem limitado, sendo que explicitamente o documento não autoriza ações militares com propósitos humanitários. Contudo, nos trabalhos preparatórios da Carta da ONU, o direito de intervenção humanitária foi debatido, ainda que não incluído no texto final" (JUBILUT, 2008, p. 136).

O resultado desse discurso é um quadro dentro do qual a ação de combate às violações em larga escala de direitos humanos se depara com sérias dificuldades tanto por razões de fato - a gravidade das violações - como por razões de ordem jurídica - designadamente as disposições da Carta já referidas.

A referida autora explica, ainda, que devido a essa lacuna entre a necessidade real e a falta de autorização para intervenções humanitárias na Carta da ONU, os Estados desenvolveram duas interpretações principais sobre o que a ausência da previsão significa. A primeira delas é a legalista, que defende que a falta de autorização expressa equivale à proibição do uso da força para propósitos humanitários. A outra consiste em uma abordagem mais holística que defende que, em função de outras previsões da Carta da ONU, da prática da ONU ao longo dos anos, da imposição de obrigações humanitárias aos Estados e, principalmente, da preocupação da própria Carta com questões relativas aos direitos humanos, a omissão não significa que haja uma proibição e que, portanto, intervenções humanitárias podem ocorrer legalmente (JUBILUT, 2008, p. 07).

Diante dessa necessidade de uso da força para propósitos humanitários, a falta de consenso sobre a interpretação da ausência de uma norma sobre intervenção humanitária e falta de posição da ONU em casos de uso da força por Estados, a inter- 
venção humanitária e, consequentemente a responsabilidade de proteger impõe incertezas legais ao sistema internacional. Ambas trazem, ainda, questões relativas à legitimidade que necessitam ser solucionada não apenas para permitir o uso da força para propósitos humanitários, mas também para evitar um enfraquecimento do sistema internacional como um todo.

Conforme o entendimento de Wheeler, a legitimidade é um elemento constitutivo das intervenções humanitárias, já que apenas as ações legítimas e plausíveis dos Estados são justificáveis (WHEELER, 2000, p. 04). O autor entende que, para que a ação seja considerada legítima, tanto no âmbito doméstico quanto no internacional, ela deve ser tomada em consonância com regras e normas aceitas e compartilhadas pelos demais Estados (WHEELER, 2000, p. 26), já que qualquer ação pode ser inibida pela sociedade internacional, se esta não for legitimada (WHEELER, 2000, p. 07).

As intervenções humanitárias seriam aceitas, portanto, quando o Estado falhasse em cumprir com suas atribuições e quando nenhum outro mecanismo existente fosse capaz de prevenir ou remediar as violações de direitos humanos que ocorressem. Ou seja, as intervenções humanitárias legitimam-se ao objetivarem a proteção de direitos humanos, mas essa proteção deve ser entendida no contexto de relativismo cultural entre os povos, e não como oriunda da universalidade aceita pela comunidade internacional.

James Pattison afirma que a legitimidade não depende da adequação das intervenções humanitárias a normas de Direito Internacional, mas sim da justificação moral dos agentes (PATTISON, 2008, p. 06). Além disso, o autor defende o caráter cumulativo da legitimidade, que é adquirida conforme se apresentam determinadas qualidades. Dessa forma, para ser plenamente legítimo, o agente precisa apresentar todas as qualidades legitimadoras (PATTISON, 2008, p. 07). Porém um 
interventor que não apresente uma delas pode ainda apresentar um nível adequado de legitimidade, dependendo das outras qualidades que ele possua. A análise dessas qualidades, e da prevalência de uma sobre a outra, pode somente ser realizada de acordo com as circunstâncias fáticas de cada caso.

Ademais, a expressão "ações incompatíveis com os propósitos das Nações Unidas", inserida no art. $2^{\circ}, \S 4^{\circ}$, reflete uma "abertura" nos termos da Carta, uma vez que o dispositivo permite incluir várias situações imprevistas e vindouras, que podem ser enquadradas na norma e permitir que a Organização atue em determinados casos. As ações incompatíveis com os propósitos das Nações Unidas são aquelas contrárias ao disposto no primeiro artigo da Carta, ou seja: a) atos contrários à paz e segurança internacionais; b) solução não pacífica de controvérsias; c) ações contrárias à autodeterminação dos povos; d) ações contrárias à igualdade de direitos dos povos, e e) violações aos direitos humanos e às liberdades fundamentais. A inclusão destas expressões demonstra a preocupação de proibir a ameaça ou utilização da força não somente nos casos de integridade territorial ou independência política de qualquer Estado, mas, em qualquer ação militar que fosse contrária aos propósitos das Nações Unidas.

Desta forma, o disposto no art. $2^{\circ}, \S 7^{\circ}$ da Carta da ONU tende a ceder frente à constatação da existência de uma ameaça contra a paz, de uma ruptura da paz ou de um ato de agressão; casos em que as Nações Unidas, por meio da atuação do Conselho de Segurança, poderão empreender ações, armadas inclusive, em conformidade com o Capítulo VII da Carta, a fim de manter ou restabelecer a paz internacional.

No mesmo sentido é o art. 39 do referido capítulo, o qual dispõe que Conselho de Segurança determinará a existência de qualquer ameaça à paz, ruptura da paz, ou ato de agressão e deverá fazer recomendações, ou decidir que medidas de- 
vam ser tomadas de acordo com os arts. 41 e 42, para manter ou restaurar a paz e segurança internacionais. (DECRETO $\mathrm{N}^{\mathrm{o}}$ 19.841, 1945).

Portanto, é da competência do Conselho de Segurança apreciar situações que possam ameaçar a paz e a segurança internacionais e determinar que medidas sejam tomadas para assegurar que os Estados cumpram, dentro de suas fronteiras, as disposições dos documentos de que fazem parte.

Diante disso, conclui-se que a resposta para o aludido conflito de normas - entre não intervenção, soberania, e intervenção humanitária - deve ser dada pelo Conselho de Segurança das Nações Unidas diante de cada caso concreto, uma vez que cabe a este órgão considerar se um determinado caso de violação aos direitos humanos se constitui em ameaça a paz e segurança internacionais, questões que se sobrepõem ao dever de não-intervenção. Frise-se que o artigo que consagra este princípio (art. $2^{\circ}, \S 7^{\circ}$ ) estabelece que as medidas coercitivas do Capítulo VII da Carta se situam acima da jurisdição dos Estados o que demonstra que, quando autorizada pelo Conselho de Segurança, a intervenção com o propósito de fazer cessar as violações dos direitos humanos em um Estado é considerada legal.

\section{CONCLUSÃO}

Ante o exposto, verifica-se que o conflito entre soberania e direitos humanos, o qual se torna ainda mais incisivo no tocante às intervenções humanitárias - visto que não há normas que as autorizem -, tem sido um dos maiores empecilhos em relação a realização de intervenções humanitárias. Isso porque a intervenção aparece, através de uma leitura literal da Carta da ONU, como exceção que somente poderá ser executada com o propósito de restabelecer a paz internacional e a segurança.

A intervenção humanitária seria aceita, portanto, quando o 
Estado falhasse em cumprir suas atribuições e quando nenhum outro mecanismo existente fosse capaz de prevenir ou remediar as violações de direitos humanos.

Assim, conclui-se que, em que pese a legalidade da intervenção humanitária, o tema ainda é extremamente controverso. No entanto, a discussão acerca de tal questão não pode ser utilizada como justificativa para a inércia dos Estados quanto à ocorrência de genocídios ou crimes contra a humanidade.

Ainda, insta ressaltar que a soberania não pode ser utilizada como escudo de proteção para evitar que se proteja e promova os direitos humanos dentro das fronteiras dos Estados, bem como que a intervenção humanitária não pode ser invocada como justificador para intervenções meramente políticas e/ou econômicas, onde sequer houve violação de direitos humanos, sob pena desta ser usada apenas para sustentar um discurso político e não humanitário.

\section{REFERÊNCIAS}

AMARAL JÚNIOR, Alberto do. O direito de assistência humanitária. Rio de Janeiro: Renovar, 2003. (Coleção Biblioteca de Teses).

BRASIL. Decreto n. 19.841, de 22 de outubro de 1945. Carta das Nações Unidas. Disponível em: http://www.planalto.gov.br/ccivil_03/decreto/1930-1949/D19841.htm. Acessado em: 21 abr. 2019.

BROWNLIE, Ian. Principles of public international law. 7. ed. Oxford, UK: Oxford University Press, 2008.

CRAWFORD, James. The creation of states in international law. 2. ed. Oxford, UK: Oxford University Press, 2006.

DAILLIER, Patrick et al. Droit international public. 8. ed. Paris, France: L.G.D.J, 2009.

DELGADO, José Manuel Avelino de Pina. Regulamentação do Uso da Força no Direito Internacional e Legalidade das Intervenções Humanitárias Unilaterais. Dissertação (Mestrado), Faculdade de Direito, Universidade Federal de Santa Catarina, Florianópolis, 2003.

FRANCK, T. Collective Security and UN Reform: between the necessary and the possible. Chicago Journal of International Law, v. 6, n. 2, Winter. 2006.

FRANÇA, Paulo Roberto Caminha de Castilhos. A guerra do Kosovo, a OTAN e o 
conceito de "intervenção humanitária". Porto Alegre: UFRGS, 2004.

FOUCAULT, Michel. A ordem do discurso: aula inaugural no collège de France, pronunciada em 2 de dezembro de 1970. Tradução de Laura Fraga de Almeida Sampaio. 5. ed. São Paulo: Edições Loyola, 1999.

GHISLENI, Alexandre Peña. Direitos humanos e segurança internacional. Brasília: FUNAG, 2011.

HERMANN, Breno. Soberania, não intervenção e não indiferença: reflexões sobre o discurso diplomático. Brasília: FUNAG, 2011.

HINSLEY, F. H. El concepto de soberanía. Barcelona: Ed. 5. Labor, 1972.

HOLZGREFE, J. L. The humanitarian intervention debate!, in humanitarian intervention: ethical, legal and politial dilemmas. Cambridge: Cambridge University Press, 2003.

JUBILUT, Liliana Lyra. A “responsabilidade de proteger" é uma mudança real para as intervenções humanitárias? Disponível em: http://www.cedin.com.br/revistaeletronica/artigos/Liliana\%20Jubilut\%20DIH.pdf. Acesso em: 03 mar. 2018.

KOERNER, A. Ordem política e sujeito de direito no debate sobre direitos humanos. Lua Nova, São Paulo, n. 57, p. 87-111, 2002.

MAIDANA, Javier Rodrigo. Contra fatos não há argumentos: Princípio da não-intervenção, ONU e Haiti, um novo estudo nas resoluções de auxílio internacional. In: Direito Internacional: análises e reflexões. Curitiba: Íthala, 2009. Disponível em: http://www.egov.ufsc.br:8080/portal/sites/default/files/anexos/33773-44089-1-PB.pdf. Acessado em: 08 out. 2018.

MACEDO, Paulo Emílio Vauthier Borges de. Direitos humanos e direito internacional. Curitiba: Juruá, 2006.

MELLO, Celso Duvivier de Albuquerque. Direitos humanos e conflitos armados. Rio de Janeiro: Renovar, 1997.

MORAES, Alexandre de. Direito constitucional. 28. ed. São Paulo: Atlas, 2012.

ONU. Assembleia Geral (1970). Res. 2625 (XXV), 24 October 1970. Declaration on Principles of International Law Concerning Friendly Relations and Co-operation Among States. 25. ed. A/RES/25/2625. Agenda 85 de 1970.

ONU. Carta das Nações Unidas (1945). São Francisco. Disponível em: http://unicrio. org.br/img/CartadaONU_VersoInternet.pdf. Acesso em: 04 mar. 2018.

ONU. Decreto n.19.841 (1945). Disponível em http://www.planalto.gov.br/ccivil_03/ decreto/1930-1949/D19841.htm. Acesso em: 24 abr. 2019.

ONU. International comission on intervention and state sovereignty (2001). The Responsibility to Protect 2001. Disponível em: htt/p://responsibilitytoprotect.org/ ICISS\%20Report.pdf. Acesso em: 05 mar. 2018.

ONU. Pacto internacional dos pacto internacional dos direitos civis e políticos (1966). Adoptado e aberto à assinatura, ratificação e adesão pela Assembleia Geral das Nações Unidas pela Resolução N. ${ }^{\circ}$ 2200-A (XXI), de 16 de Dezembro de 1966. Entrada em vigor: 23 de Março de 1976, em conformidade com o art. 49. Disponível 
em: http://www.refugiados.net/cid_virtual_bkup/asilo2/2pidcp.html. Acesso em: 21 maio 2019.

PATTISON, James. Ethics on humanitarian intervention in libya. Ethics \& international affairs, Cambridge, v. 25, n. 03, p. 271-277, set. 2008a. Disponível em: http:// journals.cambridge.org/action/displayIssuejid=EIA\&volumeId=25\&seriesId=0\&issueId=03. Acesso em: 01 mar. 2018.

PELLET, Alain et al. Droit international public. 8. ed. Paris, France: L.G.D.J, 2009.

PINTO, Simone Valente. As Nações Unias na intervenção humanitária no pós-Guerra Fria: aspectos jurídicos. Dissertação (Mestrado em Relações Internacionais), Instituto de Relações Internacionais, Pontífice Universidade Católica do Rio de Janeiro, Rio de Janeiro, 1996.

RAIC, David. Statehood and the Law of Self-Determination. The Hague, Netherlands: Kluwer Law International, 2002.

REGIS, Andre. Intervenções Humanitárias, Soberania e a Emergência da Responsabilidade de Proteger no Direito Intenacional Humanitário. Ano 5, n. 9, jul./dez. 2006.

ROBERTSON, Geoffrey. Crimes Against Humanity. The Struggle for Global Justice. New York: The New Press, 2002.

RODRIGUES, Simone Martins. Segurança Internacional e Direitos Humanos: a prática da intervenção humanitária no pós-guerra fria.Rio de Janeiro: Renovar, 2000.

WELDEHAIMANOT, Simon M. A CADHP no caso southern ameroons. SUR. Revista Internacional de Direitos Humanos. Semestral. Edição em Português. v. 9, n. 16, 2012.

WHEELER, Nicholas J. Saving Strangers: humanitarian intervention in international society. New York: Oxford University Press, 2000.

Recebido em: 30/04/2019

Aprovado em: 16/07/2019 